\title{
As Relativas Que são Fáceis Na Aquisição do Português Brasileiro
}

(The Acquisition of Relative Clauses in Brazilian Portuguese)

\author{
Maria Cecília PERroni \\ (Universidade Estadual de Campinas)
}

\begin{abstract}
"O Panchico é aquele negócio que voa e que tem um bicho que pica." (T. 4;7)
\end{abstract}

\begin{abstract}
The acquisition of Portuguese by two Brazilian children (aged 2;0 -5;0) is discussed in an attempt to describe and explain the first relative clauses produced in naturalistic, observational studies, according to the framework of generative syntax theory. The results show that at around 3;0: a) the child starts to deal with relative clauses as modifiers of $N$; b) cleft sentences appear before relative clauses, and c) the first relatives confirm the prevalence of the vernacular strategy of relativization in Brazilian Portuguese identified by other studies based on adult data.
\end{abstract}

$\boldsymbol{K} \boldsymbol{E}$-WORDs: relative clauses, acquisition, first language, Brazilian Portuguese.

REsumo: A aquisição das orações relativas por duas crianças brasileiras (entre os 2;0 e os 5;0 de idade) aprendendo o Português Brasileiro como primeira lingua é discutida, com o objetivo de descrever e explicar as primeiras relativas produzidas pelos sujeitos de estudos naturalistas, observacionais, à luz da teoria da sintaxe gerativa. Os resultados mostram que ao redor dos 3;0: a) a criança começa a construir as relativas como modificadoras do $\mathrm{N}$; b) as clivadas antecedem a aquisição das relativas, e c) as primeiras relativas ilustram a estratégia vernacular de relativização do Português Brasileiro já identificada por outros estudos com dados de adultos.

Palavras-CHave: orações relativas, aquisição, primeira língua, Português Brasileiro. 


\section{Introdução}

O título deste trabalho é propositadamente ambíguo. Uma de suas leituras corresponde à estrutura de uma sentença clivada, com redução de cópula, ou sem cópula, de acordo com o critério de Kato et alii (1996). Se presente, esta tanto pode ou não apresentar concordância, no caso da clivada com cópula invariante (Kato, 1993). Vejamos (1), (2) e (3) respectivamente:

(1) As relativas (é) que são fáceis na aquisição do Português Brasileiro.

(2) (São) as relativas que são fáceis na aquisição do Português Brasileiro.

(3) (É) as relativas que são fáceis na aquisição do Português Brasileiro.

Sentenças semelhantes a estas são de fato atestadas no registro falado espontâneo do Português Brasileiro, doravante PB (conf. exemplos encontrados em Kato et alii (1996)). Trata-se de construções muito freqüentes, apresentando cópula e focalização de um elemento da sentença.

O contexto em que tais sentenças poderiam surgir é o de um diálogo em que se discutem quais tipos de sentenças complexas são fáceis, ou difícieis, na aquisição do PB, quando um dos interlocutores opinaria: "São as relativas que são fáceis!”, ou até mesmo numa contra-argumentação a uma suposição de que as relativas poderiam ser difíceis para as crianças pequenas.

As representações propostas para as sentenças acima, com base nos autores citados, são:

(1') $[\text { As relativas }]_{\text {foc }}$ que são fáceis na aquisição do PB.

(2') EXP. $\varnothing$ são [as relativas] foc que são fáceis na aquisição do PB.

(3') EXP. Ø é [as relativas] foc que são fáceis na aquisição do PB. ${ }^{1}$

A outra leitura possível do enunciado título deste artigo corresponderia à estrutura de um DP complexo, com uma relativa propriamente dita. ${ }^{2}$

(4) [As relativas que são fáceis na aquisição do $\left.\mathrm{PB}_{\mathrm{DP}}\right]$ são o tema deste trabalho.

\footnotetext{
1 A necessidade de se postular a existência de um expletivo nesses casos não será discutida aqui.

${ }^{2}$ Esta possibilidade é prevista nos títulos de palestras, ou textos, onde se apresenta de forma resumida o assunto sobre o qual o autor vai discorrer.
} 
Sem entrar em maiores detalhes sobre as delicadas questões envolvidas nas propostas de representação das relativas (Corrêa, 1998), suponhase, para o momento, que a representação mais adequada para o DP de (4) possa ser (4'):

(4’) [As relativas $\left[{ }_{\mathrm{CP} C}\right.$ que $_{i}\left[_{\mathrm{TOP}(\mathrm{t}) \mathrm{i}}[\mathrm{IP}\right.$ pro $\mathrm{i}$ são fáceis na aquisição do PB....]]]] DP

Esta análise, baseada em Kato (1993), assume que no PB as sentenças básicas contêm uma posição de tópico discursivo (ou "left dislocation"), o que condiz com a proposta já clássica de Pontes (1987) de que o PB é uma língua tanto de tópico, como de sujeito.

Ora, ambas as estruturas aqui propostas para os exemplos de (1) a (4) coexistem na gramática do $\mathrm{PB}$ adulto, o que explica a ambigüidade da sentença título deste trabalho, que tem como objetivo contribuir, com dados naturalistas, para um melhor entendimento da questão da aquisição das orações relativas.

A análise dos dados da produção espontânea é feita com base nos pressupostos teóricos da sintaxe gerativa, no modelo hoje conhecido como de Princípios e Parâmetros (cf. Chosmky 1981, 1986, Chomsky e Lasnik 1995) e tem como objetivos principais, além de descrever e explicar tais orações, ilustrar a relação existente entre as relativas e as sentenças clivadas, e comparar os resultados com as análises já feitas por outros autores brasileiros com dados de adultos. Será feita também uma comparação entre estes dados de produção e outros, de compreensão, no intuito de identificar suas semelhanças ou diferenças.

Os dados provêm de pesquisas observacionais, longitudinais, compondo um total de 192 sessões de gravações em áudio-tape da fala das crianças com um adulto interlocutor (aproximadamente 96 horas de gravações), entre os 2;0 e os 5;0 de idade. ${ }^{3}$

A aquisição do Português Brasileiro por essas mesmas duas crianças, um menino e uma menina, já tem sido objeto de estudo há alguns anos por diversos pesquisadores ${ }^{4}$ quanto a outros aspectos de sua gramática e

\footnotetext{
${ }^{3}$ Dados do Projeto em Aquisição da Linguagem, do Departamento de Lingüística, IEL, Unicamp.

${ }^{4}$ Pesquisadores do DL, IEL, Unicamp.
} 
mostram que essas crianças diferem entre si significativamente, com relação ao ritmo de seu desenvolvimento lingüístico, de forma geral. Com efeito, a menina $(\mathrm{N})$ mostrou-se bastante precoce e tagarela desde o início, produzindo um corpus muito rico para a análise lingüística, enquanto o menino $(\mathrm{T})$ demonstrou se aproximar mais do tipo chamado por Albano (1990) de "sonhador", ou seja, a criança que fala menos, quantitativamente, parecendo estar "testando" suas hipóteses lingüísticas cuidadosamente na mente, antes de se aventurar na produção. A escolha desses dois sujeitos diferentes foi bastante consciente e proposital: advém de resultados de pesquisas anteriores, em que se constatou que as diferenças individuais exteriores (ou de comportamento observável) são enganadoras: não significam diferenças qualitativas quanto a sua gramática internalizada (Perroni, 1997). Ou, em outros termos, do ponto de vista da sintaxe, as crianças sujeito são extremamente semelhantes, evidenciando a adequação de hipóteses inatistas da aquisição da linguagem, como aquelas advindas da teoria chomskiana da sintaxe (Chomsky, 1981, 1986).

A análise dos dados foi feita através de uma comparação com outras sentenças complexas produzidas pelas mesmas crianças no mesmo período de tempo e com os critérios de Tarallo (1983), Kato (1993) e Kato et alii (1996) referentes a tipos de relativização.

A importância da função adjetiva assumida por orações relativas já foi apontada por autores como Corrêa (1989), em seu experimento sobre a compreensão de tais construções por 60 crianças brasileiras entre os 3;0 e os 6;0 de idade. Segundo Corrêa (1989), mesmo as crianças mais novas em seu estudo (3;0 de idade) lidam com as orações relativas como modificadoras do N, não parecendo haver discrepâncias entre produção e compreensão, em suas palavras. Em 1983, Tarallo constatava a inexistência de estudos sobre a aquisição das orações relativas, situação que só agora começa a se alterar.

Dessa forma, o interesse deste estudo é prioritariamente a aquisição dessas construções pela criança pequena e não o papel que as orações relativas desempenham na teoria lingüística, conforme costumava acontecer, de acordo com Corrêa (1989).

Como já exposto em trabalho anterior (Perroni, 1997), as primeiras sentenças complexas das crianças sujeitos são as estruturas com coordenação (logo após os 2;0 de idade), seguidas das clivadas, concomitantemente 
com as primeiras completivas com que aos 2;6 de idade. Vejamos alguns exemplos das clivadas:

(1) O papai que jogô fora... nu lichu... aqui. (N. 2;6)

(2) O papai que encheu. (N. 2;6)

(3) É eu que vô embrulhá pra você. (N. 3;6)

(4) T. que sabe. (T. 2;6)

(5) Só roda de jamanta que não tá. (T. 3;0)

Os exemplos acima podem ser interpretados como apresentando redução da cópula "Foi" (eg." Foi o papai que jogou fora...", "Foi o papai que encheu.”), ou “É” (eg. "É T. que sabe.", "É só roda de jamanta que não tá.”), o que se justifica também pela presença da forma hipotetizada em (3) e outras construções das crianças, da mesma época, como as seguintes:

(6) É este que é piga. ("piga" = espiga) (N. 2;6)

(7) Mas é pintinho que é piu-piu. (T.2;9)

Como se vê, trata-se de clivadas (construções É...que), que ora apresentam cópula invariante, ora omitem a cópula. São construções que salientam sintaticamente um constituinte como foco sentencial (cf. Kato et alii, 1996), neste caso, sempre o sujeito ${ }^{5}$, como o ilustram os exemplos acima. No caso de presença da cópula, esta nunca apresenta concordância, confirmando os dados de adultos, do projeto NURC analisados por Kato et alii (1996). Este fato indica que esses elementos são movidos para uma posição A-barra. Dada a função focal do constituinte clivado, uma representação possível para os exemplos das crianças pode ser como segue, propondo-se uma posição de foco à esquerda:

(1') [FocP $O$ papai ${ }_{i}\left[_{\text {foc }}\right.$ que $\left[{ }_{\text {IP }} t_{i}\right.$ jogou fora, no lixo, aqui.]]]

A alta incidência de clivadas nos dados pode ser entendida como parte de um fenômeno mais amplo, que é o da ativação das construções com focalização e topicalização. Em seu estudo com dados de um desses sujeitos (N), Grolla (2000) mostra que já aos 2;5 as primeiras construções de

${ }^{5}$ Há também nos dados clivadas de adjuntos. 
topicalização/focalização começam a surgir. Adotando a teoria proposta por Rizzi (1997) para a análise das posições chamadas de periferia esquerda da sentença, Grolla descreve cuidadosamente o percurso da criança na aquisição dos diversos fenômenos relativos às estruturas de topicalização. ${ }^{6}$

Das clivadas às primeiras relativas o passo é curto, já que ambas apresentam derivações bastante semelhantes, se considerarmos a presença de fenômenos de topicalização na gramática da criança. Além disso, convém ressaltar que as crianças já dispõem de coordenadas bem antes das subordinadas, e ainda outras sentenças complexas, como algumas completivas. Quanto à coordenação, Kato (1981) relaciona a ela o fenômeno de relativização, através da existência de elipse, bastante comum nas coordenadas, permitindo a criação de categorias vazias.

As relativas começam a se manifestar nos dados de N. perto dos 3;0 de idade e quase aos 4;0 nos dados de T., a criança menos "falante".

Como já apontado por Pontes (1987), o PB falado é uma língua que faz uso de topicalizações bastante freqüentemente, o que certamente se reflete na gramática das crianças brasileiras.

Para a análise das relativas, basear-me-ei nos autores mencionados acima, que mostram que no PB falado, existem, ao lado da relativa padrão, típica da língua escrita, a relativa com pronome resumptivo, como em "O livro que as folhas dele estão rasgadas" (ex. de. Kato et alii, 1996), e a relativa cortadora, como em "O livro que as folhas estão rasgadas" (exemplo dos mesmos autores). A cortadora é a relativa chamada por Tarallo (1983) de "gap-leaving", ocorrendo em posição de sujeito e de objeto direto. A diferença entre as duas está na opção entre a presença, ou a elipse do pronome nos contextos de co-referência.

\section{As relativas que são fáceis}

A análise dos tipos de relativas encontrados nos dados até os 5;0 de idade de ambas as crianças explorou três tipos de fatores na sua aquisição, a saber: a função do $\mathrm{SN}$ da sentença matriz, que é relativizado; o tipo de relativa (se encaixada na $\mathrm{S}$ matriz, ou se ramificação à direita) e o traço $[\underline{+}$ animacidade] do $\mathrm{SN}$ relativizado. Vejamos alguns dos exemplos:

${ }^{6}$ Para maiores detalhes, ver Grolla (2000). 
(8) Come a pedrinha qui tá 'qui. (N. 2;11) (OS) ${ }^{7}$

(9) (Era) um gatinho piquinininho, que queria tanto a mamãe dele...(N.2.11) (SS)

(10) Tem um homem que faz barulho. (T. 4;0) (OS)

(11) Só que pula um pedaço que eu não sei contar (T.4;0) (OO)

Como se pode notar nesses exemplos, as posições relativizadas são as mais baixas na árvore: as de sujeito e objeto, as quais não envolvem nenhuma preposição. Em quase 100\% dos dados é este o quadro: a posição do elemento relativizado é a mais próxima possível do relativo e até os 5;0 de idade o que surge são relativas que se constroem como ramificações à direita. Dessa forma, as construções das crianças são bastante simples, como se pode ver em suas representações, abaixo. Para sentenças como essas, segundo Corrêa (1998:142), baseada nos estudos de Kato (1993), há duas possibilidades de análise: uma correspondente a uma estratégia de relativização padrão (8”) e a outra a uma estratégia não padrão (8'):

$\left(8^{\prime}\right)$...a pedrinha $\left[{ }_{\mathrm{CP}} \mathrm{que}_{\mathrm{i}}\left[_{\mathrm{Top}}(\mathrm{t})_{\mathrm{i}}\left[_{\mathrm{IP}}\right.\right.\right.$ pro $_{\mathrm{i}}$ tá 'qui.]]]

(8") .... pedrinha $\left[_{C P}\right.$ que $_{i}\left[_{\text {IP }}(t)_{i}\right.$ tá'qui.]]

A representação (8') propõe uma estrutura de topicalização, o que é relativizado é a posição de tópico, um deslocamento à esquerda. Esta análise aproxima tais relativas das demais construções das crianças, produzidas na mesma época, como se viu nos exemplos das clivadas, de (1) a (7). A estratégia (8”) relativiza a própria posição do argumento, não prevendo topicalização.

A hipótese de que a análise (8’) é plausível para os dados das crianças pode também ser confirmada pela presença do pronome cópia em relativas de adultos e em algumas das primeiras relativas de PPs, como será visto a seguir. De acordo com Kato (1993), ao tratar as construções com deslocamentos à esquerda como predicações paratáticas de raiz (como as coordenadas), a aquisição das relativas (cortadoras, no caso) pode ser vista como uma simples extensão da sentença raiz. Parece ser isto o que ocorre nos

\footnotetext{
${ }^{7}$ Nessas notações, já empregadas por Corrêa (1989), o primeiro elemento refere-se à função gramatical do SN da S matriz, que é relativizado na relativa e o segundo corresponde à função que ocupa na relativa, (categoria vazia): $\mathrm{S}=$ sujeito e $\mathrm{O}=$ objeto.
} 
dados infantis, o que se daria, seria, portanto, a relativização da posição deslocada, como se pode ver no percurso de a) a b):
a) A pedrinha ${ }_{i,}$ ela itá qui.
DE
b) A pedrinha $\left[{ }_{C P}\right.$ que $\left[\mathrm{t}_{\mathrm{i}} \quad\right.$ [IP pro ${ }_{\mathrm{i}}$ tá quil] $]$

Dessa forma, a análise que melhor pode refletir as construções das crianças sujeito é a da relativa não padrão, como se vê em (8'), admitindose assim a presença de um pro dentro de IP, o que será evidenciado com exemplos mais tardios das mesmas crianças. Esta análise é também mais condizente com a estratégia de relativização não padrão dominante no PB falado do adulto, que é o "input" da criança, conforme atestado, por exemplo, por Corrêa (1998).

Passando à análise da posição sintática da relativa em relação à sentença matriz, nos dados de T. 100\% delas são ramificações à direita do objeto e nos de N. a grande maioria (92\%) delas é do mesmo tipo, ao lado de apenas uns raros casos de encaixamento $(8 \%)$, ou seja, ramificações à direita do sujeito, configurando um encaixamento central, como ilustrado nos exemplos abaixo:

(12) O pica-pau, que subiu no banquinho, abriu bem a tornera, ele caiu na água. (N. 3;2) (SS)

(13) Olha, esse homem que tá parecido no jornal qui chama Jararara. (N. 3;5) (SS)

Tem-se em (13) uma construção interessante: além da clivada com redução de cópula "(É) esse homem que chama Jararara", semelhante às primeiras construções da criança (cf. (1), (2) e (3)), encaixa-se aqui dentro da $\mathrm{S}$ matriz uma relativa de sujeito: "que está aparecendo (= "parecido") no jornal".

Estas porcentagens confirmam a maior facilidade da relativização à direita, conforme já apontado por Tarallo (1983) e Souza e Silva (1981), em análises de dados de adultos, podendo também confirmar o Princípio Operacional de Slobin (1985) "Forma Canônica da Oração", que prevê que se uma oração tiver que ser reduzida ou rearranjada, quando não está 
atuando como uma sentença matriz, terá sua forma canônica privilegiada pela criança, nas primeiras tentativas. Segundo o autor, a marcação aberta de todos os participantes da oração é uma característica precoce e persistente da linguagem da criança. Isto é ilustrado em seu estudo interlingüístico através da exemplicação de "erros" infantis do tipo da manutenção de um pronome cópia. Tais “erros” são cometidos por crianças adquirindo o polonês, o hebraico e o turco, que são línguas nas quais as orações relativas se afastam das matrizes, como no turco, em que consistem de nominalizações debervais que perdem os verbos finitos e a marcação de casos das matrizes.

Passando ao terceiro fator analisado, referente à natureza semântica dos $\mathrm{SNs}$ relativizados, há também uma semelhança entre as primeiras relativas das crianças sujeito. $\mathrm{Na}$ análise dos $\mathrm{SNs}$ das sentenças matrizes foram considerados os traços /+ Humano/ / /- Humano/ e /+ Animado/ / /-Animado/, representando aqui os casos de /+ Animado/ a classe dos Animados não Humanos (como “jacaré”, "cobra”, etc).

Do total dos SNs em tal posição, nos dados de N., 64,5\% são SNs [Animado], apenas $13.5 \%$ são [+Animado] e $22 \%$ são [+Humano], enquanto que nos dados de T. $74 \%$ dos $\mathrm{SNs}$ relativizados apresentam o traço [-Animado] e $26 \%$ o traço [+Humano].

Como se pode notar, a porcentagem de $\mathrm{SNs}$ relativizados contendo o traço [-animado] é a que predomina nos dados de ambos os sujeitos, com números bastante próximos, apesar da grande diferença individual existente entre as duas crianças sujeito, já mencionada na introdução deste trabalho.

Num balanço entre esses números, portanto, obtém-se que aproximadamente $70 \%$ dessas primeiras relativas são construções em que a não animacidade do antecedente prevalece. Nos dados de ambos os sujeitos apenas uma porcentagem bem menos significativa desses $\mathrm{SNs}$ relativizados apresenta o traço [+Humano], restando apenas uma pequena porcentagem de SNs com o traço [+animado]. Tal resultado pode ser entendido como um reflexo das condições de eliciação dos dados aqui analisados: os contextos de interação livre entre adulto e criança, nos quais a manipulação de brinquedos (peças de jogos, pequenos animais de plástico) era predominante. A criança tende assim a focalizar SNs que fazem referência a objetos presentes no contexto imediato, ou a tematizar os próprios participantes da interação (ela mesma, ou o adulto). 
Tarallo (1983), ao tratar dos fatores semânticos, também considera as características dos SNs cabeça de acordo com o traço / \pm Humano/ (além de singular vs. plural e definido vs. indefinido), quanto à presença ou não do pronome resumptivo, concluindo que o traço /+Humano/ favorece a presença do pronome, independentemente da função sintática do SN relativizado.

No caso aqui em estudo, a baixa ocorrência de relativas com resumptivo não confirma essa expectativa. Este fator não parece ter sido significativo neste estudo: ou seja, mesmo considerando os casos de SNs /+Animado/ ( \pm Humano) relativizados, o fenômeno do resumptivo não foi freqüente em nenhuma das posições sintáticas, o que coincide com os resultados do estudo baseado em dados do NURC, feito por Kato et alii (1996). A explicação dada por aqueles autores para tal ausência se baseou no fato de os informantes terem escolaridade alta, além da baixa porcentagem de sintagmas preposicionais relativizados encontrados nos dados (apenas 17,5\%, segundo Kato et alii, 1996:315).

$\mathrm{Na}$ verdade, as relativas copiadoras com pronome resumptivo, como já mencionado, são bem poucas nos dados, num total de apenas três ocorrências. Este resultado talvez possa ser explicado pelo fato de as funções relativizadas pela criança serem majoritariamente de sujeito (exs. (12), e (13)) e de objetos diretos (exs. (8), (10) e (11)), que são sintagmas não preposicionados em português. Com efeito, o objeto direto é a função que menos favorece o uso de resumptivos, como apontado pelos autores mencionados acima. Os únicos casos que não se enquadram nessas duas funções são ocorrências de complementos verbais preposicionais, ora com a preposição com, como em (14), ora com de, como em (15):

(14) (Conversei) ${ }^{8}$ com o homem que tava aqui. (N. 3;2)

(15) Eu também não gosto de jacaré, nem disso que você falô. (N. 3;6)

As únicas ocorrências de relativas com pronome resumptivo encontradas nos dados são:

\footnotetext{
${ }^{8}$ Este constituinte se encontra entre parênteses por ter sido produzido em enunciado com uma pequena pausa entre o verbo e seu complemento, em resposta à pergunta da mãe: "Com quem você conversou'?
} 
(16) Você queria a borsinha qui eu tava juntu cum ela? (N. 3;11)

(17) Eu vô no seu colo, porque lá tem aquela cobrinha que as muler dança nela. (N. 3;1)

(16) e (17) são exemplos semelhantes aos dos adultos, conforme atestado na literatura já mencionada (Tarallo, 1983; Kato, 1993).

Estes dados aqui analisados parecem confirmar a adequação da hierarquia de acessibilidade do SN de Keenam e Comrie (in Tarallo, 1983), da mesma forma que os estudos de Tarallo (1983), de Souza e Silva (1981) e de Kato et alii (1996). Tal proposta prevê que as posições sintáticas mais acessíveis a relativização seriam as seguintes: $\mathrm{S}$ (sujeito), OD (objeto direto), OI (objeto indireto), Obl.(oblíquo) e Genitivo, e de fato a grande maioria das relativas bem formadas neste estudo 9 é das posições de sujeito e de objeto direto. Sendo assim, uma vez que a presença do pronome resumptivo se justifica para mitigar esforço de processamento, então é mais esperável nas posições menos acessíveis, portanto, pouco prevista nos casos de sujeito e de objeto direto. Talvez seja esta a explicação mais adequada para a não confirmação da expectativa de Tarallo (1983) de que as primeiras formas de relativização a emergir na gramática da criança conteriam pronomes resumptivos. ${ }^{10}$

Uma análise adicional dos tipos de relativas produzidas pelas crianças sujeito em termos da distinção tradicional entre restritivas e apositivas/ explicativas, mostrou que a esmagadora maioria delas é de restritivas, apenas pouquíssimas podendo ser consideradas como explicativas, como a oração "qui num tá", encaixada na clivada "( foi) u meu pai qui falô", em (18):

(18) U meu pai, qui num tá, qui falô qui num tá suja. (N. 3;10)(SS)

Se a distinção entre restritiva e apositiva/explicativa se resumir a uma restrição do sentido do $\mathrm{N}$ antecedente, no primeiro caso, e ao acréscimo opcional de um atributo inerente, no segundo caso, como faz a gramática tradicional (cf.: Kury 1967), parece razoável supor que a prevalência das

\footnotetext{
9 Saliente-se que não houve casos de relativas "mal formadas".

${ }^{10}$ Uma explicação alternativa para tal ausência dos resumptivos é oferecida por Grolla (2000) que, entretanto, não será discutida aqui.
} 
restritivas se justifica pela própria função da relativa, de modificar um $\mathrm{N}$, introduzindo assim propriedades transitórias aos referentes dos $\mathrm{SNs}$, ou seja, informação nova, do ponto de vista semântico/discursivo. O fenômeno de predomínio das restritivas é também atestado em adultos, de acordo com o estudo de Kato et alii (1996), com base em dados do NURC. O fato dessas relativas restritivas contribuírem com informação nova é mais um ponto em comum com as sentenças clivadas, que são casos de focalização (nos dados infantis, sempre informação nova).

Retomando todos esses fatores, vê-se que a facilidade dessas primeiras relativas pode ser explicada por sua semelhança estrutural com as clivadas, que as precedem temporalmente, ambas originando de estruturas com constituintes deslocados à esquerda, já presentes na gramática das crianças.

Em sua proposta de descrição da periferia esquerda da sentença, Rizzi (1997), trabalhando com dados de diversas línguas, especialmente do italiano, integra no sistema de Força e Finitude as posições de Foco e de Tópico. Segundo o autor, uma vez que FocP ou TopP são ativadas, estarão inevitavelmente entre Força e Finitude, que são os dois extremos do sistema C, tal como propõe:

...Force...(Topic) ...(Focus)...FinIP... (Rizzi, 1997:7)

Se se assume tal hipótese como válida, FocP seria então uma posição bastante acessível para a criança, logo acima de IP, que obviamente já está presente na gramática dessas crianças. É exatamente isso o que ocorre nos dados: as clivadas são estruturas que focalizam um constituinte, introduzindo informação nova, com intonação bastante marcada, e surgem um pouco mais cedo que as relativas. As semelhanças estruturais entre Foco e Tópico são grandes; Rizzi (1997) propõe que o mesmo esquema configuracional dá conta de ambos.

Quanto ao Tópico, é um elemento que normalmente expressa informação velha, já disponível em falas anteriores (tanto do falante, como do ouvinte). Ao contrário de Foco, que tem uma posição estrutural única, uma oração pode conter mais de um Tópico, já que argumentos e adjuntos podem igualmente ser topicalizados. A explicação para a precedência de Foco nos dados infantis pode então ter origem tanto neste fato sintático (uma só posição estrutural), como também no fato (pragmático/discursivo) de Tópico re-introduzir informação velha. 
Um argumento a mais a favor da facilidade das primeiras relativas é o fato, a princípio intrigante, de que toda sentença complexa que contém mais de duas orações, nos dados de ambos os sujeitos, obrigatoriamente traz uma relativa (excluindo-se aqui o caso das coordenações). Alguns exemplos de T. podem ilustrar isso, além de abundantes exemplos de N., como (12), (13) (17) e (18):

(19) Eu passo tinta, que tem aquela tinta que passa por cima da outra. (T. 4;7)

(20) A B., mãe, ela ficou sem, ela num quiria ir lá na piscina, é porque ela não sabia que era o lugar de descê, era um cantinho que tinha uma pedra pra descê. (T. $4 ; 10)$

Em outros termos, a capacidade de gradualmente estender o limite de apenas duas orações, nas sentenças complexas da criança, é significativamente "facilitada" através de coordenações, das clivadas, e das relativas de sujeito e de objeto.

A análise das relativas da forma proposta por Kato (1993), aqui adotada, é bastante simples, porque defende que há relativização do tópico da sentença, aliado ao fato de que, sendo assim, o pronome relativo é sempre o mesmo para todas as funções relativizadas. Não há, portanto, indicações de que as relativas seriam, à princípio, difíceis na aquisição do PB.

\section{As relativas que são "difíceis"}

A literatura sobre a aquisição do PB dispõe ainda de poucos estudos sobre a produção de orações relativas por crianças pequenas. Por outro lado, existem já há alguns anos estudos psicolingüísticos de compreensão de relativas. Estes mostram que as crianças brasileiras podem ter alguma dificuldade com algumas delas, da mesma forma que é sabido que na aquisição da escrita o domínio de certas relativas da norma culta é particularmente tardio. É a essas relativas "difíceis" que esta seção é dedicada, com o objetivo de comparar alguns daqueles resultados com os de produção espontânea, como os deste estudo.

Começando com os estudos de compreensão de orações relativas já realizados com dados de crianças adquirindo o Português Brasileiro como língua materna, nota-se que todos mencionam que as crianças pequenas 
têm algumas dificuldades de processamento de sentenças complexas que contêm relativas.

Em 1979, Iha concluiu um experimento com 33 crianças brasileiras entre os 3;0 e os 6;0 de idade, em ambiente escolar (escola particular), testando sua compreensão de orações relativas. O procedimento adotado foi o de levar a criança a realizar em ações, com brinquedos de plástico representando animais, a informação veiculada por orações relativas produzidas pelo pesquisador, além de uma tarefa de repetição das mesmas orações.

$\mathrm{Na}$ avaliação de seus resultados, a autora afirma que houve uma tendência geral das crianças de repetir as sentenças como coordenadas, o que para ela poderia indicar o não processamento do pronome relativo pela criança. Entretanto, sua afirmação de que aquelas crianças não dominavam as relações de subordinação (cf.: Iha 1979:80) é em seguida revista pela autora, que constata que aquelas crianças de fato conheciam a função anafórica do relativo.

$\mathrm{Na}$ interpretação de seus resultados, a própria autora do experimento acima prevê que eles poderiam ser devidos às limitações do método experimental, já que "a repetição de orações... não permite que se atribua a esses enunciados uma função nem ao menos referencial” (cf.: Iha 1979:63).

Como visto na seção anterior, dados de crianças brasileiras ao redor dos 3;0 confirmam a presença das relativas na produção espontânea. As dificuldades encontradas pelos sujeitos de Iha (1979) reaparecem nos demais experimentos já realizados e não se devem somente à artificialidade da situação de experimentação, o que em si já tem sido admitido (como em Corrêa 1989 e 1996). ${ }^{11}$

Analisando os resultados de Iha (1979), note-se que os exemplos daquele experimento envolviam na construção complexa três $\mathrm{SNs}$ diferentes, todos com os traços [+animado], [- humano] (urso, cavalo, elefante, girafa), os quais poderiam, a princípio, perfeitamente preencher tanto a posição sujeito, como a de objeto dos verbos (transitivos, de dois lugares), tanto da sentença matriz, como da relativa (empurrar, seguir e pular).

\footnotetext{
11 Em seu texto de 1996 a mesma autora discute os méritos e limitações dos testes experimentais tendo em vista modelos de aquisição da gramática, comparativamente a modelos psicolingüísticos de processamento.
} 
Retome-se um exemplo de sentença SS da autora: "O urso que empurrou o cavalo seguiu o elefante". Neste caso, urso é sujeito tanto da sentença matriz, como da relativa (na $c v$ ), mas cavalo, o SN objeto da relativa, poderia perfeitamente, do ponto de vista sintático e semântico, preencher a posição de sujeito do verbo da matriz: seguir. Ou seja, nada impediria que a criança reagisse ao estímulo fazendo o objeto cavalo seguir o objeto elefante, resultado que teria que ser interpretado como inadequado, do ponto de vista da relativa oferecida, aumentando assim o total das sentenças não compreendidas.

Tais dificuldades são enfrentadas no experimento de Corrêa (1989), que parte de uma crítica aos experimentos tradicionais de compreensão que, em suas palavras, "pouco contribuem para um entendimento do processo pelo qual a habilidade de compreender estas sentenças é adquirida" (Corrêa, 1989:135).

Ao criticar os experimentos clássicos, propõe uma tarefa alternativa; criar uma contextualização para o uso das relativas, o que foi feito com brinquedos representando animaizinhos que "praticavam" ações diferentes. As crianças deveriam executar as ações com os brinquedos, depois de ouvir as sentenças com relativas. A autora testou 80 crianças dos 3;0 aos 6;0 de idade, com sentenças do tipo: SS, SO, OS e OO.

Entre suas conclusões, observa que o desempenho das crianças se estabiliza a partir dos 5;0, quando a porcentagem de respostas corretas aumenta, principalmente nas sentenças contendo um SN não animado. Neste aspecto, tais dados coincidem com os deste estudo baseado em dados de produção e com os de Da Matta (1999), comentado a seguir.

Segundo Corrêa, as sentenças do tipo SO são as mais difíceis, essas maiores dificuldades são consideradas como tendo origem na sobrecarga que tais sentenças impõem à memória. $\mathrm{O}$ mesmo pode ter ocorrido no estudo de Iha (1979), o que explicaria seus resultados negativos.

Mesmo sendo difícil comparar dados obtidos através de metologias radicalmente diferentes, com objetivos diferentes, vale a pena retomar a natureza das relativas daqueles experimentos.

Os autores citados trabalham com sentenças contendo três SNs diferentes, como: "O cavalo que pulou a cerca derruba a galinha". Do total 
dos $\mathrm{SNs}$ de todas as sentenças testadas, quatro apresentam os traços semânticos [+ animado], [- Humano], a saber: cavalo, galinha, carneiro e porco e dois o traço [- animado] (cerca e capim). Quanto aos verbos, transitivos de dois lugares, todos s-selecionam sujeitos [+animado], [ \pm Humano] a saber: pular, derrubar, empurrar, comer. Isto significa que qualquer um dos quatro $\mathrm{SNs}$ [+animado] das sentenças do experimento potencialmente poderia preencher a posição de sujeito de qualquer um dos verbos, o mesmo não ocorrendo com os de traço [-animado].

Quanto aos argumentos internos, três dos verbos são compatíveis com qualquer um dos SNs, à exceção de comer, que (nos experimentos) só admite o SN capim como seu objeto. ${ }^{12}$ Em outras palavras, a própria estrutura argumental daqueles verbos prevê a probabilidade gramatical das sentenças tanto matriz, como relativa, tanto do experimento dado, como das outras combinações com os demais SNs, como o fizeram algumas das crianças em sua interpretação inesperada do estímulo dado.

Sendo assim, as dificuldades envolvidas na compreensão daquelas sentenças aumentam, em contraste com a facilidade de produção das primeiras sentenças com relativas que, em geral, contêm apenas dois SNs diferentes. Uma análise dos verbos dos dados de produção mostra que alternam-se ali os casos de cópula, ou do existencial Ter, com verbos de ação, ora na sentença matriz, ora na relativa, de modo que a produção final não deixa margem a outras interpretações possíveis, conforme pôde ser visto nos exemplos aqui expostos.

Em outro experimento recente, Da Matta (1999) retoma a questão da compreensão das relativas, testando o desempenho de 15 crianças entre os $8 ; 0$ e os $15 ; 0$ de idade, da $1^{a}$ à $4^{a}$ séries do primeiro grau de uma escola estadual, crianças aquelas consideradas como "alunos problema". Tais resultados foram comparados com um outro grupo de crianças da mesma escola ("normais"), o chamado "grupo de controle".

Da Matta (1999) testa dois blocos de sentenças: sentenças dos “bichinhos", inspiradas no trabalho original de Corrêa (1989) e sentenças (seu

\footnotetext{
12 A esse respeito, é interessante salientar aqui o ex. (8), de N., em que a criança chega até a produzir espontaneamente um enunciado que, a princípio, poderia ser considerado não aceitável, exatamente por violar a s-seleção do verbo comer. Entretanto, se se considera o contexto lúdico em que tal enunciado foi produzido, a liberdade de combinações possíveis (gramaticais) e aceitas pelo adulto é ainda maior.
} 
chamado "segundo bloco") com SNs com traço [+humano], como: “O menino que chamou a menina abriu a porta". O teste de compreensão foi feito através de perguntas, após a leitura das sentenças com relativas. Para a sentença "O cavalo que pulou a cerca derruba a galinha", pergunta-se: "quem pulou a cerca?". A resposta, segundo a autora, permitiria verificar o preenchimento do SN relativizado, além da pergunta "Quem derruba a galinha?”, que permitiria verificar a compreensão da estrutura da sentença matriz. Os grupos de fatores testados foram: o preenchimento da categoria vazia na oração relativa, a animacidade do antecedente, e a restritividade.

Em suas conclusões dos resultados obtidos, afirma a autora que o índice de acerto foi maior no preenchimento da categoria vazia na posição de objeto, ao contrário de sua expectativa de que as relativas com categoria vazia na função de sujeito teriam um melhor desempenho.

Com relação à animacidade do antecedente, confirma os resultados de Corrêa (1989), já que o índice de acertos com o fator [+animado] foi menor do que o do acerto das relativas com SN [-animado]. De fato, Corrêa (1989) já havia previsto que este fator é significativo: as sentenças com dois SNs [+animado] e um SN [-animado] são de compreensão mais fácil do que as sentenças com três SNs, todos [+animado].

Quanto ao fator restritividade, afirma Da Matta (1999) que pareceu não interferir na compreensão das sentenças nos dois grupos de sujeitos, o que poderia contrariar, segundo a autora, a hipótese de que as relativas encaixadas centrais seriam mais difíceis à compreensão dos sujeitos do que as ramificações à direita. De fato, isso não é confirmado nos dados de produção como os deste estudo, em que as ramificações à direita (sem encaixamento na S matriz) predominam de forma quase absoluta.

Em sua interpretação de alguns de seus resultados, Da Matta (1999:119) considera que algumas diferenças de desempenho dos entrevistados "extrapolam a questão sintática". A autora comenta que os resultados diferiam quando se tratava de sentenças do primeiro grupo (aquelas dos "bichinhos"), em comparação com as sentenças do segundo grupo (aquelas com SNs [+Humano]). A interpretação da autora é que as primeiras seriam "bizarras", apesar de ambas conterem a mesma organização estrutural, as do segundo tipo estariam "mais próximas a situações vivenciadas pelos entrevistados” Da Matta (1999:120). 
Independentemente dessa possibilidade, que teria origem na metodologia adotada, convém observar que nas sentenças do grupo $1 \mathrm{da}$ autora, o mesmo fenômeno relativo à estrutura argumental dos verbos se repete. Em todos os casos havia mais de um $\mathrm{SN}$ potencialmente adequado para o preenchimento, tanto do argumento interno, como do externo.

Apesar de se basear em dados como estes, de compreensão, a autora afirma que construções com relativas "não aparecem, ou aparecem esporadicamente, em dados de produção, dada a possibilidade das mesmas serem substituídas por estruturas mais simples.” (Da Matta, 1999:147). Entretanto, tal conclusão contraria as descobertas de estudos baseados em dados naturalistas, observacionais, como os aqui explorados, em que as relativas têm um papel importante na expansão dos enunciados infantis desde os 3;0 de idade.

Relativas "difíceis" são obviamente aquelas de sintagmas preposicionais consideradas como "padrão" na bibliografia sobre o tema (cf. estratégia 8", mencionada na seção 1). Sabe-se que na língua falada, registro informal, elas praticamente inexistem nos dias atuais. Sua dificuldade é clara quando se considera a aquisição da escrita.

Isto foi demonstrado por Corrêa $(1998)^{13}$, que em seu longo estudo variacionista elaborou também uma avaliação de 50 narrativas orais e 45 escritas coletadas entre escolares do primeiro grau (da $1^{\mathrm{a}}$ à $8^{\mathrm{a}}$ série, escola pública) e informantes adultos não escolarizados. Um de seus métodos para coleta dos dados foi apresentar uma peça de teatro encenada apenas com gestos, para que os informantes reproduzissem em textos (falados, bastante informais, ou escritos) o que haviam visto.

A principal hipótese da autora, confirmada no final da pesquisa, é de que a educação formal desempenha um papel importante na variação das estratégias de relativização do PB.

Além daqueles dados, a autora comparou-os com dados de alunos do segundo grau (adolescentes e jovens), através de 90 exercícios de preenchimento de lacunas e produção livre com paráfrases. Analisou ainda dados de 15 inquéritos do NURC com adultos escolarizados.

Seu objeto de estudo são as relativas preposicionais, aqui não tratadas, por sua quase total ausência nos dados da língua falada das crianças peque-

13 Embora haja coincidência de sobrenomes, note-se que são duas autoras diferentes. 
nas. A autora compara as estratégias de relativização, tanto vernacular como padrão, segundo o critério de Tarallo (1983).

Entre seus resultados, ressalte-se que tanto os dados dos alunos do primeiro grau como os dos informantes adultos não escolarizados mostram que os mesmos usam apenas a relativa sem a preposição (estratégia vernacular), enquanto que todos fazem bastante uso das relativas de sujeito e de objeto, já presentes desde a infância, como comprovam também os dados deste estudo.

Corrêa (1998) conclui seu estudo confirmando a hipótese de que é somente no segundo grau que os jovens brasileiros vão aprender a relativa padrão, com pronome relativo e preposição.

Segundo a autora, mesmo nas relativas não preposicionais, como as de sujeito e de objeto, no vernáculo, em todas as relativas, o que se relativiza é a função de tópico, como o aqui proposto (seção 1).

\section{Conclusões}

De acordo com o exposto nas seções precedentes, os dados de produção espontânea falam a favor da facilidade da estratégia de relativização vernacular no PB falado, proposta por Kato (1993) e Kato et allii (1996), estratégia esta encontrada nos dados espontâneos de crianças ao redor dos 3;0 de idade. Assim, as primeiras relativas apresentam derivação semelhante à das sentenças clivadas e são bastante produtivas nos dados de crianças pequenas, mesmo aquelas crianças diferentes entre si, quanto ao ritmo de seu desenvolvimento lingüístico (cf. seção 1) De fato, a expansão dos enunciados infantis deve muito aos processos de coordenação, de clivagens e de relativizações, como se procurou demonstrar aqui.

Por outro lado, persistem até quase a idade adulta dificuldades com relação ao domínio da chamada relativa padrão, como o estudo de Corrêa (1998) pode comprovar, ao lado das dificuldades de compreensão de algumas relativas, como os demais estudos vistos na seção 2 podem mostrar.

Como sempre, os fatos de aquisição, comparando-se produção com compreensão, não são nunca tão simples como o pesquisador gostaria que fossem, mas, para seu desgosto, muitas vezes resistentes às suas expectati- 
vas. Alguns chegam mesmo a ser céticos sobre a possibilidade de dados de produção poderem ser comparados àqueles de compreensão. Entretanto, a teoria da gramática não se propõe como um modelo explicativo de apenas um desses lados do complexo fenômeno da linguagem, podendo contribuir para um entendimento dos fatores envolvidos nos dados lingüísticos oriundos de ambas as circunstâncias.

Como se pretendeu mostrar neste estudo, há relativas que são "fáceis" e há as que são "difíceis" na aquisição do PB, estas até mesmo para adultos. ${ }^{14}$ Identificar - e separar - essas duas possibilidades nos dados de crianças, ou adolescentes, são tarefas que dependem não só da metodologia adotada na pesquisa, do tipo da pesquisa (se sobre gramática, se sobre processamento ${ }^{15}$, como também de uma minuciosa análise da estrutura dos diversos tipos de relativas, e de suas inter-relações com outros fenômenos coexistentes (e contemporâneos durante a aquisição) na gramática dos sujeitos de cada pesquisa.

No caso das sentenças complexas com relativas, o uso de uma ou outra estratégia (vernacular, ou padrão), a estrutura argumental dos verbos (tanto da sentença matriz, como da relativa), aliada à quantidade e natureza semântica dos SNs presentes, são fatores importantes, quer para a sua facilidade, quer para sua dificuldade.

\section{REFERÊNCIAS Bibliográficas}

Albano, E.C. (1990) Da Fala à Linguagem, Tocando de Ouvido. S. Paulo: Ed. Martins Fontes.

Chomsky, N. (1981) Lectures on Government and Binding. Dordrecht, Foris (1986) Knowledge of Language Its Nature, Origin and Use. N.Y.: Praeger.

ChOMsky, N. e H. LASNIK (1995) The theory of principles and parameters. In: Chomsky, N. (1995) The Minimalist Program. Cambridge: The MIT Press.

CorrêA, L. M. S. (1989) Porque as relativas são de difícil compreensão para a criança? D.E.L.T.A., 5.2:133-148.

\footnotetext{
${ }_{14}$ Retome-se, para isso, o estudo de Corrêa (1998) que analisa dados até de adultos escolarizados.

15 Como bem aponta Corrêa (1996), já comentado anteriormente.
} 
(1996) Dificuldades e potencialidades do uso do método experimental no estudo da aquisição da linguagem In: M.F. de CAstro (org.) O Método e o Dado no Estudo da Linguagem. Campinas: Ed. da Unicamp. CorrêA, W. R. (1998) Oração Relativa: O que se Fala e o que se Aprende no Português Brasileiro. Tese de Doutorado. DL., IEL, Unicamp, Campinas.

Da MatTA, S.S. (1999) Um Estudo sobre a Compreensão de Oracões Relativas com Crianças em Idade Escolar. Dissertação de Mestrado, Univ. Federal do Paraná, Curitiba.

Grolla, E. B. (2000) A Aquisição da Periferia Esquerda da Sentença em Português Brasileiro. Dissertação de Mestrado. DL. IEL, Unicamp, Campinas.

IHA, S. (1979) Compreensão de Orações Relativas por Crianças de três a seis anos. Dissertação de Mestrado. DL., IEL, Unicamp, Campinas.

Kato, M. A . (1981) Orações relativas: variação universal e variação individual no Português. Estudos Lingüisticos V: 1-16. PUC- São Paulo.

Kato, M. A. (1993) Recontando a estória das relativas. In: Kato, M.A. e I. Roberts (eds.) Português Brasileiro: Uma Viagem Diacrônica. Campinas: Ed. da Unicamp.

Kato, M. A., M.L. Braga, V.R. Corrêa, M.A. Lopes Rossi, N.S. Sikansi (1996) As construções -Q no português brasileiro falado: perguntas, clivadas e relativas. In: Koch, I. G.V. (org.) Gramática do Português Falado Vol. VI. Desenvolvimentos. Campinas: Ed.da Unicamp.

Kury, A. da G. (1967) Lições de Análise Sintática. S.P.- R.J.: Ed. Fundo de Cultura.

Perroni, M.C. (1996) Primeiras sentenças complexas na linguagem da criança. Estudos Lingüísticos. Vol. XXVI: 709-715. Unicamp, Campinas (1997) Relatório ao CNPq. de bolsa de produtividade em pesquisa.

Pontes, E. (1987) O Tópico no Português do Brasil. Ed. Pontes, Campinas.

Rizzi, L. (1997) The fine structure of the left periphery. In: L. HAEgEMAN (ed.) Elements of Grammar. Kluwer Academic Press.

SLOBIN, D. I. (1985) The Cross-Linguistic Study of Language Acquisition. LEA. Hillsdale, N.J.

Souza e Silva, M.C.P. (1981) Orações Relativas: Dificuldades na Produção Escrita. Tese de Doutorado, PUC /SP.

TARAllo, F.L. (1983) Relativization Strategies in Brazilian Portuguese. Tese de Doutorado, Universidade da Pensilvania. 